\section{Dear Colleagues}

It is a great pleasure to announce the final program and, in particular, the surgical highlights of the 11th United European Gastroenterology Week (UEGW) to be held in Madrid from November 1 to 5, 2003.

Christoph Beglinger, chairman of the scientific committee of UEGF, succeeded in organizing an excellent scientific program including 42 symposia, 24 lunch and 28 free paper sessions presenting original work. He strongly encouraged the surgical societies to work together and increase the Gl surgical participation and surgery-related topics in this important united gastroenterology meeting.

Representatives of ISDS, EAES and EDS as well as EPC and EACP combined their efforts so that many surgery-related symposia are included in the program which will provide extensive new surgical information during the congress.

Important surgical symposia on Monday include: Ethics in liver transplantation, in particular livingrelated liver transplantation; management of duodenal adenomas in FAP, the pancreas-preserving duodenectomy; management of neuroendocrine tumors and treatment of fistuling in Crohn's disease.

Tuesday is starting with an interdisciplinary symposium on the management of colorectal liver metastases, followed by new developments in the treatment of colorectal carcinoma. In the afternoon, there is a symposium on intraductal papillary mucinous tumors of the pancreas and multimodality approach to pancreatic carcinoma, as well as ileoanal pouch surgery and morbid obesity.

Other symposia on Wednesday include management of acute pancreatitis; fecal incontinence, and management of GERD.
During the meeting, four different postgraduate courses are being organized.

Together with EAGE, the surgical societies ISDS, EAES and EDS will organize a joint 11/2-day postgraduate course on 'New developments in diagnosis and management of early and advanced GI malignancy' coordinated by Professors Guido Tytgat and Freddy Penninckx.

This excellent program is printed separately and will provide new information limited and extended endoscopic and (laparoscopic) surgical procedures for different GI tumors including liver and bilio-pancreatic malignancies. The participants of this postgraduate course will obtain a scientific syllabus with detailed information about all included subjects.

The congress venue is the Palacio Municipal de Congresos in Madrid, the traditional capital city of Spain, and the meeting will be organized by Professor Javier Piqueras, Chairman of the local organizing committee (website: www.uegf.org/uegw2003).

The UEGW will provide excellent circumstances to be the important meeting in the near future for the exchange of knowledge between the different areas of gastrointestinal diseases.

The surgical representatives of ISDS, EAES and EDS would like to invite our surgical colleagues to participate in this important meeting and to further increase the collaboration between surgery, gastroenterology, hepatology as well as other participating societies.

We do need more surgical participation during this excellent gastroenterology week.

$\begin{array}{ccc}\text { DirkJ. Gouma } & \text { Alberto Montori } & \text { Freddy Penninckx } \\ \text { Representative } & \text { Representative } & \text { Representative } \\ \text { EDS } & \text { EAES } & \text { ISDS }\end{array}$




\title{
Combined
}

\section{EAGE, ISDS, EDS and EAES Post Graduate Course \# 7 Saturday 1st and Sunday 2nd November, 2003}

\section{New developments in diagnosis and management of early and advanced GI malignancy}

\author{
Course organizers: G.N. Tytgat (EAGE); F. Penninckx (ISDS, EDS, EAES)
}

\section{SATURDAY, NOVEMBER 1}

\section{AFTERNOON SESSIONS}

14.00-15.40 SESSION I: UPPER GI MALIGNANCY

Chairmen: $\quad H$. Obertop (Amsterdam, The Netherlands)

L. Lundell (Stockholm, Sweden)

14.00-14.20 Critical appraisal of staging of (early) gastro-esophageal lesions I. Penman

14.20-14.40 Indication for endoscopic mucosal resection or photodynamic therapy in superficial esophageal tumors

C. Ell (Wiesbaden, Germany)

14.40-15.00 Indications for minimally invasive surgery Abe Fingerhut (Poissy, France)

15.00-15.20 The role of induction chemotherapy J.R. Siewert (München, Germany)

15.20-15.40 Extended resection for esophageal cancer J.J.B. van Lanschot (Amsterdam, The Netherlands)

15.40-16.00 Coffee break
16.00-17.40 SESSION II: BILIO PANCREATIC MALIGNANCY

Chairmen: M.W. Büchler (Heidelberg, Germany) P. Malfertheiner (Magdeburg, Germany)

16.00-16.20 Critical appraisal of staging bilio-pancreatic tumors

D.J. Gouma (Amsterdam, The Netherlands)

16.10-16.40 Endoscopic endosonographic approaches of bilio-pancreatic lesions Th. Rösch (München, Germany)

16.40-17.00 Surgical treatment of pancreatic cancer J.P. Neoptolemos (Liverpool, UK)

17.00-17.20 Surgical approach for bile duct tumors J.B. Belghiti (Paris, France)

17.20-17.40 Any role for photodynamic therapy S. Pereira (London, UK) 
SUNDAY, NOVEMBER 2

MORNING SESSION

\subsection{0-12.00}

SESSION III:

\section{GENERAL ONCOLOGY}

Chairmen: G.N. Tytgat (Amsterdam, The Netherlands)

A. Fischer (Copenhagen, Denmark)

8.30-8.50 What should the clinician/surgeon know about molecular oncogenesis? H. Blum (Freiburg, Germany)

8.50-9.10 Is there a role for probiotics in cancer prevention?

F. Shanahan (Cork, Ireland)

9.10-9.30 Does laparoscopic surgery influence immune suppression and tumor recurrence? H.J. Bonjer (Rotterdam, The Netherlands)

9.30-9.50 To what extent will $H$. pylori eradication reduce gastric cancer?

A. Axon (Leeds, UK)

9.50-10.10 Is Barrett adenocarcinoma a preventable disease?

L. Lundell (Stockholm, Sweden)

10.10-10.40 Coffee break

10.40-11.00 How to solve the gastric cardia conundrum? K. McColl (Glasgow, UK)

11.00-11.20 The role of surgery in prevention of familial cancer syndromes of the Gl tract H. Friess (Heidelberg, Germany)

11.20-11.40 Is the novel grading/staging of neoplasia useful?

K. Geboes (Leuven, Belgium)

11.40-12.00 Endoscopic mucosal resection for early digestive cancer H. Ono (Shizuoka, Japan)

\section{AFTERNOON SESSIONS}

\subsection{0-15.10 SESSION IV:} SECONDARY LIVER TUMORS

Chairmen: $\quad$ R.A. Adam (Paris, France) R. Arnold (Marburg, Germany)

13.30-13.50 Imaging/staging of secondary liver tumors by MRI and PET

C. Matos (Brussels, Belgium)

13.50-14.10 Local ablative therapy for liver metastasis R. Lencioni (Milan, Italy)

14.10-14.30 Laparoscopic treatment of liver metastasis D. Cherqui (Paris, France)

14.30-14.50 Primary and repeated resection of liver metastasis R.A. Adam (Paris, France)

14.50-15.10 Interstitional laser coagulation A. Vogel (Frankfurt, Germany)

15.10-15.30 Coffee break

15.30-17.30 SESSION V:

Chairmen: M.R. Keighley (Birmingham, UK) M. Farthing (Glasgow, UK)

15.30-15.50 Critical appraisal of staging of rectal tumors R.G. Beets-Tan (Maastricht, The Netherlands)

15.50-16.10 Endoscopic management of early colorectal lesions

B. Saunders (London, UK)

16.10-16.30 The limits of the laparoscopic approach towards colo-rectal cancer A. Lacy (Barcelona, Spain)

16.30-16.50 Multimodality treatment of advanced rectal tumors

L. Pahlman (Upsala, Sweden)

16.50-17.10 The role of stenting as temporary and palliative treatment M.C. Parker (Dartford, UK)

17.10-17.30 Surgical cytoreduction and intra-operative hyperthermic intra-peritoneal chemotherapy in colorectal peritoneal carcinomatosis A.J.Witkamp (Amsterdam, The Netherlands) 